\title{
ICT FOR DEVELOPMENT, EMPOWERMENT, OR EMANCIPATION? A REFLECTION ON TERMINOLOGY BASED ON CASE STUDIES IN UNDERSERVED COMMUNITIES OF CAPE TOWN
}

\author{
Maria Rosa Lorini and Wallace Chigona \\ University of Cape Town \\ Rondebosch, Cape Town, South Africa
}

\begin{abstract}
A University research project sparked, followed, and analysed three processes of social and human development that unfolded in urban underserved communities in Cape Town, South Africa. The processes developed over three years through a flexible approach to outcomes connected with the use of information and communication technologies. A series of final questions drives the analysis of the evaluation of this multiple-case study. What were the processes about? What did the processes do? What did they bring about? What is the legacy of these projects? These questions are analysed through the explanation of the evolution of the case studies presented. The most important question about the intentions of the participants - researcher, external professionals and community members- connects with their philosophical background and assumptions. Seldom stated, occasionally externalised in the approach to interventions, the reasons to participate in a project are the most likely determinants of its outcomes -development and/or empowerment and/or emancipation- and nevertheless the less evaluated. The paper claims that the elucidation of the terminology stimulates the reflection over ideologies and motivations that drive research and activities.
\end{abstract}

\section{KEYWORDS}

Development, Empowerment, Emancipation, ICT4D

\section{INTRODUCTION}

In academia terminology misuses and abuses are common. This is generally due to simplifications, popularity or convenience, while synthesising complex contexts with unclear boundaries (Castellví, 1998). Occasionally a paragraph or note is added, mentioning the complexity of the term, justifying with space constrains the impossibility to deepen explanation.

In the field of Information and Communication Technology for Development (ICT4D), over the last thirty years, the term 'development' has been used commonly without any reference to its history or its meaning. This, despite the complexity of the term development and the not homogenous use in the different disciplines and amongst practitioners. In the last two decades, a dialectical tension emerged between a macro approach focused on national economic development and the approach that focuses on human development (Ranis et al., 2000). Development does not anymore correspond solely to economic growth and westernization (Mehmet, 2002). In different scenarios of economic, social, political and personal development, studies show how certain issues are cross-border and unite high-GDP countries and lower and middle income countries (LMICs). Inequality growth, rising unemployment, and illiteracy are not limited to the once so-called developing countries (Cingano, 2014). For the sake of better explanations, other terminologies have emerged over time. They are valid in different economic and cultural contexts, and usually, they bear different ideological references. The terms 'emancipation' and 'empowerment' are among the ones primarily used in specific contexts, such as in the feminist debate (Hafkin \& Huyer, 2006).

In the context of information systems and technology we observe a generic and sometimes interchangeable use of such terms (Lincoln et al., 2002). In this way, the specificity and possible contribution of the meaning of the words to the phenomenological analysis is therefore compromised. When choosing 
theoretical frameworks for reference and support, the value and meaning of the words are often underestimated and the choice of a conceptual approach risks to be accomplished without the assessment of the ideology behind it (Denzin and Lincoln, 2013).

In an attempt to elucidate some inevitable assumptions or deficiencies associated with ICT4D, a presentation of a multiple case study will follow focusing on its evaluation. Evaluation was based on the questions developed prior to fieldwork, in particular, 'What kind of contribution can ICT4D projects make'; questions posed throughout the process and related to the specific context; and, finally, following the work carried out: 'What kind of contribution did the projects make for different participants?'

In the research field of ICT4D, the expected contributions are connected with development, which, as stated above, is sometimes referred to as empowerment or emancipation, depending on the framework of reference. We have to consider whether the desired contribution is aimed at economic development, in the classical sense (Ranis \& Fei, 1961); or if the research claims to support the integral human development (Alkire, 2010); or if development represents the increased capacities to act and the ability to choose (Sen, 1999); or if it is emancipation from discrimination, constraints and ideological, political and social super-structures (Macdonald, 2015). These questions can be answered from different ontological perspectives and still bring similar results; preliminary questions, on the other hand depend on the participants' philosophical background. While analysing critically specific case studies, this paper reflects on the question that lies behind the ontological and methodological choices and that is often neglected: 'What are the intentions of the participants?' In the case studies, an emergent and flexible approach allowed for receptiveness from all participants' objectives, while continuous reflection on action allowed participants' roles and goals to evolve.

A synthesis of the development terminology in literature highlights potential aims in ICT4D projects. The paper continues with the introduction of embedded case studies representatives of ICT4D projects. The evaluation of the analysis of the findings about the participants' intentions let emerge the importance of the methodology chosen and of the reflective practice approach. The conclusion emphasises the importance of assessing if values and intentions of every participant had been respected, independently of the possible development, empowerment or emancipation goal reached.

\section{AN EVOLVING TERMINOLOGY}

The word development came into being after World War II to formalise a series of conditions of countries with low GNP, limited economic growth with structural changes (Gore, 2000), limited governance systems (dictatorships and possible new coups d'état expected) (Olson, 1993) and limited infrastructure investment (roads, hospitals, schools, etc.) (Agénor, 2010). Already at that time, GNP was considered as insufficient index, due to the lack of income distribution data (Marrama, 1958). From 1990, the United Nations Development Program introduced the Human Development Index to measure the quality of life and the social wellbeing in the countries on the base of the expectations of life, education and income (Sagar \& Najam, 1998).

While the terminology connected with the division into first, second, third and fourth worlds was questioned at the end of the eighties with the end of the Cold War, together with the 'underdeveloped countries' concept (Berger, 1994), the new terminology of developed and developing countries emerged. The developing countries were the ones with low and middle income groups, compared to the developed countries with high income groups. The distinction is still used despite a certain disagreement emerging from the LMICs. In the debate, the Wold Bank suggested to interrupt its use (Khokhar \& Serajuddin, 2015). Meanwhile, new words gained consensus.

Empowerment is one of those words that in the last two decades gained success (Wilkinson, 1998). While development seemed too complex to envisage as the aim of a short-term project, the empowerment of the participants seemed to be more realistic and affordable. Empowerment becomes a means towards the wider end - development (Parpart, 2002). The terminology, empowerment, reflects a real and tangible improvement in the life of the involved person or in its quality, without assuming an integral approach to the complexity of the context (Friedman, 1992). While development became associated with an economic, social, cultural and political change, empowerment could focalise on the limited uplifting of an individual or a group in a determined context (Perkins \& Zimmerman, 1995). 
A more limited impact in the recent development literature, had the word emancipation. While strongly addressed by the critical social theory as the main desired outcome for any process (Devetak, 1996), it has an historical background and a political flavour that discourage many researchers from adopting it. While development and empowerment seem socially recognised as significant for every person in every country, emancipation seems connected with past realities, when slavery was still in vogue (e.g. in South Africa, Dooling, 2007), and later on when political dissidents and women were fighting for changes (Azmanova, 2009; Dolphyne, 1991). Moving beyond that tradition, emancipation can be interpreted as the reached capability of a person to freely decide on the base of her own values and knowledge and in connection with her community (Steinberg and Kincheloe, 2010).

The terminologies, once explained, instead of being interchangeably, suggest a complementarity: the structural changes of society required to enjoy the freedom that emancipation implies could be achieved through social, economic and political development projects. In turn, empowerment -as the more ad personam approach to development- can become the leading instrument to emancipation.

In the ICT4D field, the debate around terminology and intentions created an initial reaction with the possibility to choose whether using the ICTD expression (ICTs in developing countries) or the ICT4D one (ICTs with development aims) (Brown and Grant, 2010). In future, the 'D' may refer to any conditions that need to be improved or modified in any region of the world. This approach will help to dismiss judgement of secondary importance of what comes from the once-called developing countries, such as reverse innovation, products referred to as 'good enough' (Govindarajan \& Ramamurti, 2011).

\section{CONTEXT AND PARTICIPANTS}

The case studies developed in the underserved urban areas of Cape Town, South Africa, specifically in the informal settlements growing inside and around the townships, the once designated areas for non-whites. The groups that participated in the research are based in the poorest sections of the surroundings, where the majority of the population inhabits shacks without running water and formal electrical cables. Philippi, where most of the activities took place, has $44.3 \%$ formal dwellings, and with only $26,7 \%$ of the homes having piped water (Statistics SA, 2011). The area has a limited number of facilities for pre-school children, whereas schools are usually overcrowded. Hospitals and clinics, another major infrastructural element of development, are unable to serve the growing population coming from the rural areas (Jacobs \& Du Plessis, 2016). Unemployment is a national issue that reaches $31.9 \%$ of youth at country level and scores $38 \%$ in Philippi, where more than half of the population lives under the poverty line surviving with less than 120 euros per month (Statistics SA, 2011). At national level, HIV prevalence is $19.2 \%$, compared to the world $0.8 \%$ (WHO, 2017; USAIDS, 2015).

In this context where infrastructural, economic and social development issues are striking and development projects appear to be essential, different networks of people have emerged and succeeded in recreating social ties, in order to cope with the lack of services and in order to support each other (Haddad $\&$ Maluccio, 2003). Hundreds of women became part of mass movements that use daily savings and loan practices as a tool for social mobilisation. Through door-to-door collection of small change, communities create flexible, home-grown financial structures that fulfil a critical economic gap and provide a social safety net to ensure the availability of funds for basic survival (Bolnick, 1993). The ritual of daily savings fulfils also a social need, reducing isolation among women and fostering community trust. The groups participating in the study are part of the Women's Network, coordinated largely through community-to-community learning exchanges. These horizontal learning initiatives allow women to see themselves and their peers as experts, thereby reducing isolation, improving confidence, strengthening solidarity and increasing critical mass.

Similar to women, youth living in these underserved communities are trying to organise themselves. In Philippi, where the projects developed, as well as in the neighbouring townships, unemployment and exclusion lead to frustration, lack of income, and 'boredom', making it easy for young people to turn to drug abuse and crime (Wegner et al., 2006). The informal Inyanda Youth Network is a collective of groups, interested in organising edutainment activities (education through entertainment), associated with positive messaging (e.g., on HIV-AIDS through hip-hop or drama). 'Inyanda', in the local Xhosa language, is a bundle of wood. The bundle comprises of various small and bigger pieces of wood found in different places. In the same way, the Youth Network consists of a multitude of groups from different townships intended bring warmth to the townships thanks to the strength of togetherness. 


\section{CASE STUDIES - EVOLVING PROCESSES}

\subsection{Women Groups}

At the beginning of 2014, six groups of women of the Women's Network took part in the exploratory phase of a research project through interviews and focus groups. At the end of the year, two groups of Mamas, as they are usually called in their communities, participated in the creation of digital storytelling to present their activities and to use new technologies that might support their own groups. The emergent approach chosen supported the possibility to develop an unfolding process that evolved in time, allowing all the participants to reflect and decide on their roles and intentions. As a result of activities and encounters, the women requested training in computer literacy and in the use of several common applications. The training had a long preparatory analysis of the way to introduce novelty and on how to interact. It took place in June 2015 , with 10 women from five different groups taking part in the activity. In November, they requested a follow-up to another organisation in order to strengthen their technological knowledge and to improve their skills. At the beginning of 2016, some of the women became co-trainers to support new training on basic computer skills for other women in their community. In May 2016, they presented some of the results of the process at a university seminar. They explained their approach to technology in their own words, showing great understanding and ownership of the process and of skills acquired, as well as great strength and self-esteem in addressing for the first time an academic audience. To this day, the women are still supporting the organisation which helped them mobilising youth to attend training.

\subsection{Youth Groups}

In 2014, five groups of youth contributed to the research exploratory phase through focus groups and interviews. At the end of the same year, three of the groups participated in the creation of digital storytelling that evolved into a motivational video for youth. In 2015, a series of workshops took place involving different youth groups and a number of professionals, such as web designers and event organisers, in order to evaluate and improve youth skills. In particular, the aim of some workshops was to organise an event where skills, resources and tools of the different groups were analysed to verify the strength of the network and of each group commitment to continue working together, offering a service to the community. At the same time, other workshops for the creation of a website for the network and for the individual groups developed, while several members acquired new skills. In 2016, a follow up analysis of the outcomes of the activities carried out during the previous year, was done. It showed how some groups strengthened their connections and capacities to collaborate, as it was verifiable from the number of events organised in the community and from the number of followers that the groups reached on Facebook. The main projects developed are Philippi Music Project, The Bridge Experience, Poetics not for the sake of it, and the re-launch of the network that gathers the different subgroups: the Inyanda Youth Network. In 2016, some youth representatives also participated in the presentation organised at the University where they elaborated on their capabilities and specifically on some of the ICT knowledge they had developed thanks to a series of training, such as the one they attended on applications' creation. Some of the projects are now becoming economically self-sustainable.

\subsection{Community Radio Station Group}

One of the five youth groups participating in the research at the beginning of 2014 was particularly interested in ICT; its members expressed their desire and dream to create a radio station for the community. Their project was described and presented through a digital storytelling which illustrated the process done by the group from the moment the idea was conceptualised to the creation and opening of a pirate community radio station in July 2014. In 2015, a series of workshops were organised at the request of the radio station founders. A number of people attended the activities: founders, community listeners of the radio, technicians and professionals who wanted to support the team to make a difference. The external experts who participated in the realisation of the workshops were researchers, professional journalists and web designers. 
The workshops developed around the theme of ethics in journalism, community activism and, on the technical side, on the creation of a website to reach out to more people, expand the visibility of the station and become more professional.

The team also used the opportunity to start utilising a new application, in order to broadcast from outside the radio station, directly from the community. The project continued evolving in 2016 when the founders of the community radio station decided to request a licence from the government. At the same time, some of the founders decided to register their local organisation in order to continue working with the community and not to lose the momentum created by the radio station activism. That same year, the radio station team presented the results of their activities at a University seminar and used the opportunity to try to develop new contacts and networks. The licensing process required the temporal suspension of the activities, which restarted once the radio became legally registered and economically sustainable.

\section{PROCESSES’ ACHIEVEMENTS}

\subsection{Women’ Groups}

The Women embraced from the beginning of the research the new activities suggested and after a brief exposure to new ICT tools, they requested to strengthen their skills. Their persuasion, commitment and enthusiasm are a testament to their desire to continue their empowering path. They used the new opportunity to increase their capacities to support their communities and engage in social activities. In addition to their motivations, the endorsed computer training had an empowering focus on strengthening their capacities, making them feel at ease and secure, and supporting the growth of their self-esteem connected with their ability to develop and apply new skills and to increase their knowledge. The trainers never put pressure on participants but rather worked with them, at their own pace, giving them full attention and ad hoc one-on-one coaching. The follow-up training reinforced a process initiated directly by the women. Their capacity to independently plan, schedule and elaborate it with the participation of a new training organization is further proof of the empowerment gained throughout the process.

This project develops into a fully rounded process of development. The main intention driving the women was their desire to keep on supporting their community, and they used an inclusive approach, inviting more members and new groups to participate in the follow up phases. Furthermore, the women evaluated every option available to affect their society without focusing on their individual or group benefit. Thanks to the empowerment of the participants, and thanks to the perspective they maintained to make a difference for their community, this project is still ongoing, still evolving and producing new results.

Concerning the possible progress in women emancipation through ICTs activities, in time new skills led to an enhanced perception of self and to a stronger ability to interact with their surroundings and peers through the use of technology. The Women were able to continue the process without the support of external experts. They discussed and agreed on what could be useful, self-determining the follow-up steps. A full emancipation process might require further steps for the development of decision-making capabilities based on the inner values and knowledge.

\subsection{Youth Network and Radio Station Group}

The workshops the youth decided to engage in allowed them new opportunities. In particular, the participants could gain additional knowledge and further develop plans they were already working on. Empowerment was represented here was the possibility to strengthen the network and visualize connections and ties between individual groups digitally. In the long term, the process strengthened their relationship and trust and the feeling of shared social responsibility. The same happened to the radio station process, when the group engaged with community members to discuss further possibilities through a website or smartphone applications.

Development-wise, the youth network aimed to potentiate its capabilities to reach out to more youngsters, capitalising on their skills and expertise. The outcomes of the activities carried out were oriented towards the community, beyond the groups participating. The process of development is evolving, growing and 
aggregating more youth in the network experience, as proven by social media and events' participation. Concerning the radio station group, its members reinforced ties and commitment to their community through the process of registration of the radio station and of their new organization, founded in order to access more opportunities.

An examination of the emancipatory process could be done for the network as well as for the single groups. The growth of the network and the empowerment of the single groups, like the radio station one, allowed an occasion for members to increase the sense making, contemplate their reasons for coming together and for participating, as well as an occasion to ameliorate their collective decision-making system. Their capabilities and reinforced self-assuredness developed in time, strengthening self-consciousness and desire to achieve set objectives. The aims of each group remained separated and connected with their passions and desires. Nevertheless, for all of them, it was possible to analyse and see increased consciousness and determination to reach out personal and community objectives.

\section{DISCUSSION}

The evaluation of the projects and of their outcomes was based on participant observation, interviews with community members and with development professionals operating in the same context, feedback by external observers indirectly involved in the projects, and social media use analytics. These evaluation tools were used both during the course of the projects, once the same had ended, and a few months after that, in order to validate the analysis' results. The findings present several elements of empowerment, development and emancipation that emerged along the processes. In order to fully evaluate projects outcomes, an in depth analysis of participants intentions and aims is required.

In the cases presented, given also the community-based nature of these action research projects, a grassroots emergent approach more easily supported valorisation and disclosure of participants' values and strengths (Krauss, 2012). The choice of letting processes unfold allowed participants to empower themselves; over the course of the projects, participants developed new skills, deepened their knowledge, took significant decisions and undertook specific responsibilities for their future (Razak, 2009).

To support a path of emancipation, focused on self-consciousness and determination, the projects included context and culture specific approaches during the technical workshops and trainings, that matched and respected participants' cultural background and values. Strengthening the community specific local mechanisms of empowerment and approaching projects with a perspective of mutual respect and mutual learning, allowed participants to shape and pursue their own motivations and goals, disconnected from forms of cultural imperialism (Stahl, 2006). This further allowed not only for ICTs based empowerment, but also for the beginning of emancipatory dynamics.

In the cases presented, an emergent approach was initially used to best establish the focus of the ICTs support interventions. Such emergent approach then allowed to avoid potential risk factors associated with the development of counterproductive solutions (Lin, Kuo \& Myers, 2015). An analysis of how groups and individuals operate and cooperate in that particular context, as well as an analysis of their values, best directed the projects. The visualisation of those elements allowed the participants to understand options, choose, and lead the change To fully impact communities and individuals, ICT4D processes require such an analysis, and not only an assessment study.

A reflection over terminology is crucial also in the process of evaluation. What people want to achieve, the reason for the same and their preferred approach are strictly linked on their values and ideology. In every process it is essential to define the intentions and expectations of participant-researcher, external professionals and community members, as well as the overall objective, which in the case studies presented was namely: development, empowerment, emancipation.

\section{CONCLUSION}

The main concept and contribution the author wished to develop is the importance of the use of specific terminology and the explicit disclosure of ideological and theoretical frameworks adopted. Terminology used reflects choices made and the intentions behind the same. Clarifying intentions underlying the choice to 
study, analyse, operationalise and evaluate ICT4D projects, supports dialogue with similarly minded researchers, and diminishes possible misunderstandings with or misrepresentation by researchers working from within different theoretical frameworks.

The focus of several ICT4D projects may be on infrastructural or technical aspects; others may focus more closely on developmental aspects of the same. Regardless of such focus, results analysis will be based on the selected philosophical framework and the questions raised, which will justify selected approaches. Likewise, weather the research focus is on human development, economic development, technical development, defining terminology used in research and in presenting analytical results fosters a fuller understanding of the work.

The cases in the long term, generated a number of results, evaluated on the basis of criteria directly derived from initially expressed intentions and newly risen ones. The intentions were discussed with and within the community participants as well as participating external experts, notwithstanding potential difficulties in truthfully establishing each participant's personal and group objectives.

The study underlines the key importance of defining framework, intent, focus and terminology used, in each and every ICT4D research project.

\section{ACKNOWLEDGMENT}

The paper is part of the main author PhD dissertation "Collective empowerment through information and communication technologies: co-creation processes in underserved communities in Cape Town" (Lorini, 2018). Faculty of Commerce, Department of Information Systems, University of Cape Town, South Africa. http://hdl.handle.net/11427/30004.

In the thesis, the 'Women Groups' are referred to as 'Mamas groups', as the women referred to each other in their communities. I am grateful I was asked by the participants to address them in that same familiar way, and I am grateful to all the participants for their engagement during the processes.

\section{REFERENCES}

Agénor, P. R. (2010). A theory of infrastructure-led development. Journal of Economic Dynamics and Control, 34(5), 932-950.

Alkire S. 2010. Human Development: Definitions, Critiques, and Related Concepts. Human Development Research Paper HDRP/2010/01. New York: United Nations Development Programme.

Azmanova, A. (2009). 1989 and the European Social Model: Transition without emancipation? Philosophy \& Social Criticism, 35(9), 1019-1037.

Berger, M. T. (1994). The end of the 'Third World'? Third World Quarterly, 15(2), 257-275.

Bolnick, J. (1993). The People's Dialogue on Land and Shelter: community-driven networking in South Africa's informal settlements. Environment and Urbanization, 5(1), 91-110.

Brown, A. E., \& Grant, G. G. (2010). Highlighting the duality of the ICT and development research agenda. Information Technology for Development, 16(2), 96-111.

Castellví, M. T. C. (1998). Do we need an autonomous theory of terms? Terminology. International Journal of Theoretical and Applied Issues in Specialized communication, 5(1), 4-19.

Cingano, F. (2014). Trends in Income Inequality and its Impact on Economic Growth. OECD Social, Employment, and Migration Working Papers, (163), 0_1.

Denzin, N. K., \& Lincoln, Y. S. (Eds.). (2013). The landscape of qualitative research: Theories and issues. Sage.

Devetak, R. (1996). Critical theory. Theories of international relations, 145-173.

Dolphyne, F. A. (1991). The emancipation of women: an African perspective. Ghana Universities Press, Accra, Ghana.

Dooling, W. (2007). Slavery, emancipation and colonial rule in South Africa (Vol. 87). Ohio University Press, Ohio.

Friedman, J. (1992). Empowerment: The Politics of Alternative Development. Blackwell, Oxford.

Gore, C. (2000). The rise and fall of the Washington Consensus as a paradigm for developing countries. World development, 28(5), 789-804.

Govindarajan, V., \& Ramamurti, R. (2011). Reverse innovation, emerging markets, and global strategy. Global Strategy Journal, 1(3-4), 191-205. 
Haddad, L., \& Maluccio, J. A. (2003). Trust, membership in groups, and household welfare: Evidence from KwaZulu-Natal, South Africa. Economic Development and Cultural Change, 51(3), 573-601.

Hafkin, N. J., \& Huyer, S. (2006). Cinderella or cyberella?: Empowering women in the knowledge society. Kumarian Press, Bloomfield, CT.

Jacobs, W., \& Du Plessis, D. J. (2016). A Spatial Perspective of the Patterns and Characteristics of Main- and Substream Migration to the Western Cape, South Africa. In Urban Forum (Vol. 27, No. 2, pp. 167-185). Springer, Netherlands.

Khokhar, T. \& Serajuddin, U. (2015) "Should we continue to use the term "developing world"?", available at: http://blogs.worldbank.org/opendata/should-we-continue-use-term-developing-world (accessed: January 2016).

Kleine, D., \& Unwin, T. (2009). Technological Revolution, Evolution and New Dependencies: what's new about ICT4D? Third World Quarterly, 30(5), 1045-1067.

Krauss, K. (2012). Towards self-emancipation in ICT for development research: narratives about respect, traditional leadership and building networks of friendships in rural South Africa. The African Journal of information systems, $4(2), 1$.

Lin, C. I., Kuo, F. Y., and Myers, M. D. (2015). Extending ICT4D studies: The value of critical research. Management Information Systems Quarterly, 39(3), pp.97-712.

Lincoln, N. D., Travers, C., Ackers, P., \& Wilkinson, A. (2002). The meaning of empowerment: The interdisciplinary etymology of a new management concept. International journal of management reviews, 4(3), 271-290.

Macdonald, B. J. (2015). Critical Theory. In The Encyclopedia of Political Thought. 1-9, M. T. Gibbons (Ed.). Wiley Blackwell.

Marrama, V. (1958). Saggio sullo sviluppo economico dei paesi arretrati (Vol. 23). Edizioni Scientifiche Einaudi, Torino, Italy.

Mehmet, O. (2002). Westernizing the Third World: The Eurocentricity of economic development theories. Routledge.

Olson, M. (1993). Dictatorship, Democracy, and Development. American Political Science Review, 87(03), 567-576.

Parpart, J. (2002). Lessons from the field. Rethinking empowerment gender and development from a post-(post-?) development perspective. In: Feminist post-development thought: rethinking modernity, postcolonialism and representation, edited by Saunders. 41-56, Zed Books. London, England.

Perkins, D. D., \& Zimmerman, M. A. (1995). Empowerment theory, research, and application. American journal of community psychology, 23(5), 569-579.

Ranis, G., \& Fei, J. C. (1961). A theory of economic development. The American economic review, 533-565.

Ranis, G., Stewart, F., \& Ramirez, A. (2000). Economic growth and human development. World development, 28(2), 197-219

Razak, N. A. (2009). Empowering the rural communities via the telecentres. European Journal of Social Sciences, 9(3), 425-432.

Sagar, A. D., \& Najam, A. (1998). The human development index: a critical review. Ecological economics, 25(3), 249-264.

Sen, A. (2001). Development as freedom. Oxford Paperbacks, Oxford.

Stahl, B. C. (2006). Emancipation in cross-cultural IS research: The fine line between relativism and dictatorship of the intellectual. Ethics and Information Technology, 8(3), 97-108.

Statistics SA (2011). "My settlement: Philippi", Statistics South Africa, available at: http://www.statssa.gov.za/?page_id=4286\&id=323 (accessed: January 2017).

Steinberg, S. R., \& Kincheloe, J. L. (2010). Power, emancipation, and complexity: Employing critical theory. Power and Education, 2(2), 140-151.

UNAIDS (2015). "HIV and AIDS estimates" (2015), available at: http://www.unaids.org/en/regionscountries/countries/southafrica (accessed: January 2017).

Wegner, L., Flisher, A. J., Muller, M., \& Lombard, C. (2006). Leisure boredom and substance use among high school students in South Africa. Journal of Leisure Research, 38(2), 249.

WHO (2017). "HIV-AIDS”, available at: http://www.who.int/gho/hiv/en/_accessed: January 2017).

Wilkinson, A. (1998). "Empowerment" in M. Poole, and M. Warner (Eds.). International Encyclopaedia of Business and Management Handbook of Human Resource Management, ITB Press, London. 